\title{
EL INTERÉS DE LOS RELATOS ESCOLARES EN LA FORMACIÓN DE LOS MAESTROS DE EDUCACIÓN INFANTIL
}

\author{
Interest of school narratives in Early Childhood Inicial Teacher Education \\ O interesse dos relatos escolares na formação dos educadores infantis
}

\author{
Marcelino Juan Vaca Escribano \\ Universidad de Valladolid. España. Facultad de Educación de Palencia. Telf.: \\ 979108269. Correo electrónico: mvaca@mpc.uva.es
}

\section{Resumen}

Los relatos escolares tienen en nuestro caso un largo recorrido, nacieron de la necesidad de tener algún documento que nos permitiera analizar con detalle y fiabilidad lo ocurrido en nuestras propias prácticas. Progresivamente, su elaboración fue necesitando de la colaboración de un observador externo.

En este artículo se analiza una experiencia de trabajo compartido entre una maestra y su "amigo crítico", en la que se analiza como los relatos escolares pueden llegar a ser un recurso importante en la formación del profesorado, no solo en la formación permanente, sino también en la formación inicial, en este caso de los Maestros de Educación Infantil.

Palabras clave: Relato escolar, formación de maestros, análisis de la práctica, educación infantil.

\footnotetext{
Abtract

The school narratives we write have a long history. They were born from the necessity of producing texts that allow us to analyse with detail and confidence what used to happened in our practices. As they evolved, the narratives requiered the collaboration of a external observer.

This paper presents a collaborative experience between a teacher and her critical friend that shows how school narratives can be an important resource for teacher education at different stages; in this case, for earlychildhood teachers in the initial stages.

Key Words: school narratives, initial teacher education, practice analysis, early childhood education.
} 


\section{Resumo}

Os relatos escolares que escrevemos têm um longo trajecto, nasceram da necessidade de ter algum tipo de documento que nos permitisse analizar com minucia e fiabilidade o que acontece nas nossas aulas praticas. À medida que avançamos foi neceserio introduzir um observador externo.

Neste artigo analiza-se uma experiencia de trabalho entre a Professora e o seu "amigo critico", na qual é analizado como os relatos escolares podem chegar a ser um recurso importante na formação dos futuros professores ou educadores, não só na formação permanente, mas também na formação inicial, neste caso na formação dos Educadores Infantis.

Palavras-chave: relato escolar, formação de professores, analise de situações practicas, educação infantil

\section{Introducción}

Son los hombres nuevos del Imperio los que creen en comienzos desde cero, capítulos nuevos, páginas en blanco; yo persevero en la misma historia, con la esperanza de que antes de que concluya me revele por qué creí que merecía mis desvelos.

J.M. COETZEE "Esperando a los bárbaros" La vida en el aula va construyendo historias en las que pueden observarse las relaciones que se establecen entre el alumnado, el maestro y los temas motivo de enseñanza y aprendizaje. Nos referimos a ellas como relatos escolares. Como maestro y, después, como profesor universitario dedicado a la formación de los maestros siempre he estado interesado por estas historias, por observarlas, narrarlas, escucharlas, compartirlas..., sin duda estas tareas son parte importante en mi desarrollo profesional.

Al principio, los relatos eran frases sueltas, a veces una fotografía, e incluso una sola palabra cogida a vuelapluma en el transcurrir de la práctica con la intención de pensar después sobre lo ocurrido, compartir su alcance, reorientar la práctica siguiente... Después, siendo ya profesor universitario, pasaron a tener otro ritmo, era posible un mayor sosiego al observar esos momentos de la vida escolar a los que había sido invitado por el maestro o la maestra responsable. 
Desde mediados de los setenta hasta finales de los ochenta, los relatos elaborados hacían referencia a la vida escolar en general. Ejercía como maestro y en aquellos años todos éramos maestros generalistas, no obstante, mis relatos siempre tuvieron un sesgo determinado, y es que aunque todos los maestros ejercíamos como generalistas, las procedencias y formación tenían matices diferentes que enriquecían el intercambio educativo en el centro. El sesgo de mis narraciones se debía a mis estudios de Educación Física y a que el grupo de maestros en el que de forma prioritaria las compartía era el Seminario de Psicomotricidad 2-8 años del Colectivo de Renovación Pedagógica ADARRA-BILBAO.

A finales de los ochenta pasé a ser profesor titular de la escuela de magisterio de Palencia. Al curso siguiente a mi llegada ya contaba con un seminario de maestros de infantil y primaria interesados por el Tratamiento Pedagógico del ámbito Corporal, lo denominábamos Seminario TPC. Había dejado de ser un maestro generalista para pasar a ser un profesor universitario ligado a un Área departamental determinada: "Didáctica de la Expresión Corporal". El tratamiento educativo del cuerpo, la actividad motriz y la cultura motriz pasaron a ser el objeto de mi trabajo, no obstante siempre he mantenido una perspectiva de escuela básica, general y obligatoria, que acoge un cuerpo que actúa, se expresa, aprende y va adquiriendo competencias a lo largo de toda la jornada escolar.

Durante la primera década como profesor universitario utilicé la tarde de los lunes para dar clase de manera voluntaria en un centro público de infantil y primaria, el CEIP "Ramón Carande" de Palencia. Por esta experiencia, se interesó vivamente el área de Programas de la Dirección Provincial de Educación y ello hizo que contáramos con el responsable de medios audiovisuales para filmar las lecciones desarrolladas. La experiencia presentó muy pronto sonoros inconvenientes: el tratamiento educativo del ámbito corporal reclama atención a lo largo de todo el tiempo que el alumnado permanece en la escuela y, sin embargo, la experiencia se reducía a esa hora semanal en la que las criaturas participaban de una lección impartida por un adulto que tan solo veían en ese momento. El compromiso de analizar juntos las lecciones impartidas en esa hora en la que el profesorado debía permanecer en el centro, libre de alumnado, se fue diluyendo como lo hace un terrón de azúcar en un vaso de agua. Pero también presentaba algunas ventajas que no quería desaprovechar. Podía ver la película filmada cuantas veces quisiera a lo largo de la semana, para relatarla con detalle ajustándome a lo filmado y analizarla con diferentes intenciones, como: precisar el proyecto de la 
lección siguiente; narrar lo ocurrido para analizarlo en el Seminario TPC; observar las reacciones a mí trabajo por parte de los maestros tutores.

Como la experiencia mantuvo su desarrollo sistemático durante tres ciclos escolares (en principio solo estaba pensada para un curso), fui aprendiendo a: dar clase delante de una cámara, elaborar relatos coordinados con las imágenes filmadas, analizar relatos sobre las lecciones enlazadas que nos permitían estudiar el conjunto de la unidad de aprendizaje, reflexionar sobre el desarrollo de la Programación General Anual, tomar notas sobre la Propuesta Curricular elaborada para el ciclo educativo, identificar las estrategias pedagógicas que se mostraban más pertinentes... Todo ello me fue muy útil en mi profesión de formador de maestros.

Por fin, en el noveno curso, se dio ese hecho que esperaba ocurriera al finalizar el primero, una de las maestras de educación infantil se interesó por cambiar el rol conmigo. Y esto provocó, entre otras muchas cosas, que progresivamente, otros miembros del Seminario TPC comenzaran también a considerar oportuno invitarme a observar y filmar sus prácticas en momentos que mis horarios lo permitían.

A partir de este punto de inflexión, los relatos escolares se centraron en tramos de la vida escolar a los que yo asistía como observador externo. Filmaba y elaboraba desde las imágenes tomadas relatos escolares que compartía con el maestro o la maestra responsable. Un buen número de ellos eran analizados en las sesiones semanales del Seminario, atendiendo una triple intención acordada:

- Identificar los contenidos de la educación corporal: Qué enseñar, su por qué y para qué.

- Colaborar con el maestro responsable en su deseo de mejorar la propia práctica, clarificando hipótesis e identificando las estrategias pedagógicas más acordes a poner en marcha.

- Detectar y, en la medida de lo posible atender, las demandas de formación que el maestro responsable mostraba.

En los últimos años de la última década de los noventa y en la primera de los dos mil hemos desarrollado las actividades de formación permanente del profesorado en el Seminario TPC con estas premisas, en diferentes contextos educativos.

En Educación Infantil, la primera maestra en invitarme a ser observador externo de su trabajo fue Marisol Varela Ferreras. Durante un año había sido ella observadora 
de las lecciones que yo impartía en el CEIP "Ramón Carande" de Palencia, a las que ya me he referido. Cuando, al año siguiente se hizo cargo de una tutoría, consideró oportuno ser ella quien impartiera las lecciones en mi presencia y no al revés. Trabajamos juntos en la planificación, en el análisis y en la evaluación, analizando de forma compartida los relatos escolares que yo iba elaborando; la conducción de cada una de las lecciones correría de su cuenta ${ }^{1}$.

En Educación Primaria, he sido observador externo durante varios años de las lecciones que impartía Mercedes Sagüillo Rodríguez, maestra especialista de Educación Física, que formaba parte del Seminario TPC desde sus orígenes en Palencia.

Como observador externo, al igual que en el caso anterior, me procuraba un lugar desde el que poder tomar imágenes de lo que estaba sucediendo, en el que molestara lo menos posible (En cuanto pasaban unos días, creo no exagerar si afirmo que pasaba prácticamente inadvertido para el alumnado). Los relatos escolares pasaron a ser transcripciones de la vida escolar que filmaba y fotografiaba, que enviaba a Mercedes en DVD y texto, con algunas anotaciones en cursiva sobre mi parecer sobre lo que había sucedido. Buena parte de estas filmaciones y los relatos escolares ilustrados que las describían fueron motivo de exposición y análisis compartido en el Seminario $\mathrm{TPC}^{2}$

En natación escolar, he sido durante varios años observador externo de las lecciones que impartía Inmaculada Prieto Flores (Inma), que forma parte del grupo de monitores de natación escolar contratados por el Patronato Municipal de Deportes del Ayuntamiento de Palencia para llevar adelante las Campañas de natación escolar y que también formaba parte del Seminario TPC.

Como en los casos anteriores, los relatos escolares eran transcripciones de las lecciones que fotografiaba y filmaba, y que enviaba a Inma en DVD y texto, con

\footnotetext{
${ }^{1}$ Sobre este proyecto publicamos en la revista Cuadernos de Pedagogía, $\mathrm{n}^{\mathrm{o}} 353$, enero de 2006; y publicamos también el libro: Motricidad y aprendizaje. El tratamiento pedagógico del ámbito corporal (3-6). GRAÓ (Biblioteca de infantil: 25). Barcelona. ISBN. 978-84-7827-676-9. (234 páginas). En esta publicación pueden verse numerosos relatos escolares que ilustran nuestra manera de entender y llevar a cabo el tratamiento educativo del ámbito corporal en aquellas circunstancias y que son utilizados por diferentes profesores universitarios en sus actividades de formación de maestros en relación con la educación corporal.

${ }^{2}$ Como en el caso anterior, también hay alguna publicación que da cuenta de la experiencia desarrollada a través de los relatos escolares elaborados. Ver: Revista: Educación física y deporte. Instituto Universitario de Educación Física. Universidad de Antioquia. Volumen 28-1 2009. Pp. 85-102. "El tablero en las lecciones de Educación Física Escolar. Su contribución al aprendizaje".
} 
algunas anotaciones en cursiva sobre mi parecer sobre lo que había sucedido para comentarlo en la elaboración del nuevo plan de lección. ${ }^{3}$

Ha habido ocasiones en las que he confeccionado relatos escolares en visitas puntuales, tanto en España como en Francia. En Francia, destacaría el trabajo realizado, durante algo más de una década, con Brigitte Onillón, maestra de una escuela infantil y, a la vez, profesora del Instituto Universitario de Formación de Maestros de Nantes. En todas las visitas a las que me han invitado como observador externo he procurado que hubiera tiempo para exponer y analizar juntos el relato escolar elaborado.

Durante todo este proceso, aproximadamente dos décadas, los relatos escolares, elaborados a partir de las imágenes filmadas, se iban transformando en piezas concretas, que ayudaban junto a la visión de las imágenes a intercambiar sobre aspectos importantes del oficio de maestro: la estructura de las lecciones; la relación entre las diferentes situaciones educativas; la progresión en habilidades y desarrollo motor; el papel de los maestros; los ingredientes que construyen un ambiente que facilita el aprendizaje... En los relatos escolares de lecciones enlazadas se identifican con facilidad las hipótesis que se encuentran en el pensamiento del maestro responsable, su comportamiento ante el comportamiento diverso del alumnado; los aprendizajes, de diferentes tipos, que el alumnado construye.

En este artículo, que como es sabido versa sobre el interés de los relatos escolares en la formación de los maestros, me detengo en una en una experiencia concreta, desarrollada en el CEIP "Miguel Hernández" de Valladolid durante los cursos 2011-2014, una experiencia que se inicia, teniendo en cuenta lo ocurrido en las experiencias anteriores, sus posibilidades e inconvenientes..., como un proyecto personal de formación permanente solicitado por Susana Fuente Medina, maestra de Educación Infantil, vinculada al Seminario TPC e interesada por el estudio y la gestión del ámbito corporal y sus repercusiones en el proyecto educativo que trataba de poner en marcha en el segundo ciclo de educación infantil con un nuevo grupo de niños y niñas.

\footnotetext{
${ }^{3}$ También en este caso buena parte de los relatos escolares ilustrados fueron motivo de exposición y análisis compartido en el Seminario TPC y han sido numerosas las publicaciones realizadas en las que pueden observarse abundantes relatos escolares elaborados. La última: La integración de las actividades motrices acuáticas en la educación física escolar. Edita: Patronato Municipal de Deportes. Ayuntamiento de Palencia en colaboración con la Universidad de Valladolid. ISBN: 84-689-0057-5. (160 páginas)
} 


\section{Los relatos escolares en la Experiencia del CEIP “Miguel Hernández"}

En el inicio del curso escolar 2011-2012 decidí atender una propuesta, que se me venía formulando desde hacía tiempo por parte de una maestra del Seminario TPC: Susana Fuente Medina. Me proponía ir a su centro de trabajo, un día de la semana y en un tramo de horario que fuera compatible con el mío, con la intención de estudiar conjuntamente el interés educativo del ámbito corporal en su aula. Iniciaba, otra vez, el segundo ciclo de Educación Infantil, 3-6 años.

Voy a obviar alguna información sobre este Proyecto de indagación educativa para, ir directamente a la metodología de desarrollo, en la que cobra una relevancia particular los relatos escolares como estrategia de formación de los maestros.

La franja horaria que compartíamos era de 12.00 a 14.00 horas. La primera hora se desarrollaba en el aula habitual y la segunda en la sala-gimnasio, que, a su vez, era el comedor del colegio.

En principio, la duración del proyecto sería la del curso escolar, pero al finalizar éste vimos que era posible continuar y abarcar el ciclo completo, 3-6 años. La única diferencia fue que durante los cursos 2012-2013 y 2013-2014 el día de la semana cambió a los martes, para hacerlo compatible con mi horario, y que durante el último curso, 2013-14, hubo que dejarlo en el mes de febrero dada mi carga en el segundo cuatrimestre.

Cuando llegaba al centro el alumnado se encontraba en el tiempo de recreo, generalmente en el patio. En su vuelta al aula pasaban por los servicios para asearse. Les visitaba en el patio y les acompañaba en su regreso al aula.

Comenzaba a filmar cuando entraban en el aula. Además de filmar en vídeo tomaba algunas fotografías. Me comportaba como un observador externo que acompaña la vida escolar, pero que no interviene en el desarrollo de la práctica educativa. No hablaba con nadie, el alumnado no se dirigía a mí, lo que no me impedía observar algunas miradas de complicidad a las que procuraba no responder.

Durante los tres cursos reservé la tarde del día de visita para elaborar una transcripción de aquello que la cámara había captado. Cuando en la transcripción se me ocurría alguna pregunta, comentario, sugerencia, referencia bibliográfica..., que pretendía que no se me olvidara tratar en el encuentro de la tarde de los jueves con 
Susana, lo escribía en letra cursiva. Esa misma tarde, enviaba el texto construido a Susana por correo electrónico. Le enviaba también una copia en pdf en la que el mismo texto estaba ilustrado con algunas de las fotografías tomadas.

Los miércoles era yo quien recibía un correo de Susana en el que me adjuntaba el texto que yo le había enviado con sus explicaciones, comentarios, preguntas..., escritas en color azul.

Durante la tarde de los jueves nos veíamos en la Facultad de Educación de Palencia para analizar juntos los documentos que habíamos intercambiado y comentar los dibujos que los niños habían elaborado sobre la lección en la sala-gimnasio, con dos intenciones principales: Compartir el análisis y las reflexiones personales sobre cómo mejorar la práctica educativa de la semana siguiente y conversar sobre las demandas que Susana planteaba en relación con su quehacer profesional. En su vocabulario cambió la expresión observador externo por la de "amigo crítico", quizá estaba influida por la lectura de Eisner (1998).

Susana utilizaba algún tiempo del resto de la semana para añadir al relato nuevos párrafos, ahora en verde, con aquellas cuestiones que habíamos compartido y que tenían que ver con: las respuestas a las preguntas formuladas, el debate sobre los comentarios que habíamos introducido en el relato, la oportunidad que se le veía a las sugerencias expresadas, el interés que despertaban las referencias bibliográficas señaladas.

Recibía el documento con "los verdes" la mañana de los lunes, en broma, denominábamos a esta última versión "relato arco iris", y, junto a él, me llegaba el plan elaborado para la semana siguiente.

La memoria del desarrollo del proyecto da cuenta de la disciplina seguida en el proceso metodológico apuntado, apenas ha habido alguna semana en la que no hayamos realizado el ciclo tal como le he explicado.

Adjunto, a continuación, el primer relato escolar elaborado. Téngase en cuenta que en estas fechas la jornada escolar es más corta y, más aún, cuando se trata de niños y niñas de tres años. 
Relato escolar 26.09.2011.

Periodo de adaptación 3 años. Primera visita, finales de septiembre...

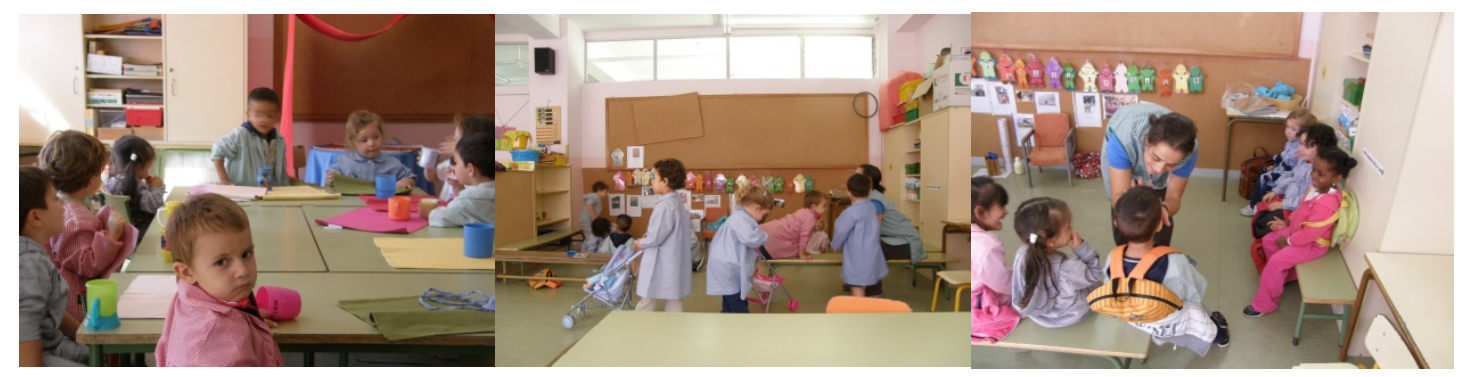

Foto 1

Foto 2

Foto 3

Comienza la película con los niños y niñas en el aula, sentados en dos grupos de mesas, no todos... Se han ido colocando en su mesa particular un tapete/mantel con la ayuda de la maestra, la ayuda es diferente en cada caso. Cuando prácticamente todos están acomodados, la maestra comienza el reparto de tazas/vasos. Muestra la taza y, a veces, su dueño la reconoce... “Tengo otro vasito, ¿de quién es?”, dice cantando la maestra. Hay muy pocos que digan "mío" claramente...

El canto ayuda a mantener ese ambiente de tensa calma, aunque no todos están concernidos en la tarea si lo están en la cantinela de la maestra.

Con una botella grande reparte un poco de agua en cada vaso... Mientras esperan a que les llegue el turno uno de los niños golpea con el vaso la mesa, ahora son dos los que golpean, pronto son tres, cuatro... Al parecer basta cualquier iniciativa para que otro la imite. "Arrímate a la mesa...", se oye decir a la maestra.

Tengo la sensación de que todo puede descontrolarse en cualquier momento.

“Quiero más", dice un niño... "Por favor", le corrige la maestra.

Mientras esperan a que pongan agua en su vaso, algunos juegan con el mantel... Recursos de ayuda: botellas pequeñas no muy llenas para que puedan hacerlo ellos y no tengan que esperar...

La maestra saca una caja con mochilas, dentro de ellas hay un yogurt, o natillas, o un plátano..., lo va repartiendo, también ha de repartir cucharillas... De nuevo se da ese tiempo de espera que algunos no aguantan sentados y que hace que la maestra tenga que estar a varias cosas a la vez... 
La espera a recibir atención... La diversidad de los alimentos hace que cada niño sea un mundo que reclama atención individual...

[Foto 1] Aún está repartiendo mercancía cuando un niño se levanta a dejar/recoger/ordenar el tapete/mantel. Él ya ha terminado de desayunar...

El ritmo personal, el ritmo compartido... ¿?

Van recogiendo los tapetes, entregando las mochilas a la maestra, tirando a la papelera lo sobrante...y se van, la mayoría al lugar de agrupamiento.

La dificultad de los enlaces de una situaciones educativa a otra...

Uno de los niños se arrastra por los bancos del corro del lugar de agrupamiento, mientras algunos de sus compañeros siguen desayunando. La maestra trata de estar a todo y a cada caso, gestionando el guion y atendiendo lo que surge espontáneamente. Hay un niño que se termina de comer el plátano en el lugar de agrupamiento...

El ritmo personal, el ritmo compartido ... ¿?

¿Permitir comer en el lugar de agrupamiento?

Además de gestionar el proyecto general la maestra atiende diferentes incidentes: el que una niña haya derramado el agua, el que otra, en vez de comerse las natillas las haya vertido en el mantel; el que un niño llore porque otro le ha cogido el carrito que él llevaba... Y, un instante después, vemos a la maestra dando de comer a un niño que aún no había terminado, luego a otro...

Necesitas “dos manos”, una para el proyecto general, otra para lo que surge...

Los niños giran entre dos lugares-acción: una especie de casita, en la que entre otras cosas hay un teléfono, y el ya nombrado lugar de agrupamiento en el que tienen a mano puzzles, cochecitos, muñequitos...

Hay algunos carritos que transportan muñecos de un lugar a otro, o por el “camino verde" (una línea en el suelo que había pintado la maestra). [Foto 2]

Las criaturas se entretienen de diferentes modos y la maestra atiende, supongo que más por lo que la exigen, que por iniciativa propia... ¿? Un niño se cae del banco... Van de un juego a otro, de un libro a otro, con ritmos diferentes, a unos parece durarles más la intención, a otros muy poco... Hay niños con juguetes o libros del corro en las 
mesas en las que antes habían desayunado... Les hay que se entretienen solos y quienes tienen dificultades para estar entretenidos y reclaman atención personal.

No parece que se pueda tener otro plan que no sea atender cuestiones básicas de seguridad y justicia en este tiempo de juego libre...

Susana les invita a recoger y, cuando ya hay más orden, se suma a los bancos del lugar de agrupamiento, participando en "un tren" que los niños y niñas han formado sentándose a horcajadas.

Después de un tiempo, se forma un corro. El lugar de agrupamiento contiene una conversación en la que se cuentan incidentes: la caída de los bancos de uno de los niños...

El responsable del grupo está sentado en la silla alta... La maestra va pasando por el grupo poniendo un poquito de colonia a cada uno a la vez que dice su nombre (Es la colonia del responsable, cada niño tiene en el aula un tarro de colonia). Algunos no esperan sentados, pero sí la mayoría.

Reparte las mochilas y se las ayuda a poner a cada uno...

Cuando ya están todos más o menos preparados, la maestra dice en voz alta: "El beso del cocodrilo", construye con las dos manos una "boca de cocodrilo" con la que acaricia la cara de cada uno [Foto 3]. Las criaturas esperan sentados a que les llegue el turno. A la vez que les da este particular beso, les pregunta: “¿te espero mañana?”, con una amplia y singular sonrisa le van "diciendo" que sí vendrán.

Los niños están muy expectantes a lo que va pasando con cada uno de sus compañeros.

Es un momento de calma, muy afectivo, en el que la atención personal de la maestra parece atrapar el interés de todos...

Van construyendo "un tren" para salir, una fila en la que cada uno va agarrado al de delante...

Con la Experiencia del CEIP "Miguel Hernández" siguieron cambiando los relatos escolares, tanto en su elaboración como en el uso, nunca hasta ahora habían sido utilizados para iniciar un intercambio entre una maestra y un profesor universitario con la intensidad descrita. Los relatos escolares que íbamos confeccionando estaban disponibles para el profesorado del centro y en ocasiones se analizaban en el Seminario 
TPC, pero la exigencia era tan fuerte que de manera global pasó a ser cosa de dos, la maestra tutora y su amigo crítico.

Hasta ahora, buena parte de los relatos escolares elaborados se habían expuesto y analizado en las reuniones del Seminario TPC y habíamos hecho referencia a ellos en algunas publicaciones, como he explicado. Pero con los elaborados en la Experiencia del CEIP “Miguel Hernández”, quizá por la riqueza del archivo, porque ya habíamos utilizado relatos escolares de forma puntual en la asignatura "Educación Física Escolar" en el Grado de Maestro de Educación Primaria; quizá porque Susana pasó a ser profesor asociado en la Facultad de Educación y Trabajo Social de Valladolid en los estudios de educación infantil; ... o simplemente, porque lo vimos más claro y comprendimos que leer el relato, ver la película desde la que lo habíamos elaborado, y volver al relato para analizarlo juntos era una buena estrategia, también para la formación inicial.

Esencialmente leer es sostener una relación a la vez recreativa y competitiva con el texto del escritor. Es una afinidad sumamente activa, cooperadora y sin embargo, también agonística, cuya ejecución lógica, si no real, es un "texto de respuesta”.

Steiner $(2006,18)$

El caso es que nos decidimos a utilizar los relatos escolares en la formación inicial de los maestros, concretamente en la asignatura obligatoria "Fundamentos y Didáctica de la Educación Corporal Infantill", que se imparte en tercer curso, segundo cuatrimestre, en el Grado de Maestro de Educación Infantil. Es la primera y única asignatura que cursan los estudiantes de Educación Infantil en relación con la Educación Corporal.

\subsection{Los relatos escolares en la formación inicial de los maestros de Educación} Infantil

A comienzos del curso 2014-2015 hicimos los cálculos pertinentes, ya que los relatos escolares elaborados en la experiencia eran muchos y la carga de la asignatura se limitaba a dos módulos de dos horas semanales durante quince semanas. El primero de los dos módulos semanales en los que se imparte la asignatura se dedica a la teoría. El segundo es el módulo de práctica, en el que la ratio de estudiantes es la mitad del grupo de teoría. Pretendíamos que una de las actividades a desarrollar en el módulo de teoría fuera el visionado de la película desde la que se había transcrito el relato escolar que, 
como ya hemos dicho, les había sido enviado días antes para que pudieran hacer sobre ellos una lectura comprensiva y exponer las preguntas que el relato les suscitaba. Los estudiantes tendrían la oportunidad, en el módulo de práctica, de volver con sus preguntas y continuar con el análisis del relato escolar iniciado en el módulo de teoría.

Decidimos que los temas a tratar fueran los siguientes:

Tema 1. El ámbito corporal en el Periodo de adaptación escolar.

Los estudiantes contaban con los pdf de los relatos escolares ilustrados de fechas: 26.09.2011 (relato expuesto más arriba) y 3.10.2011, y verían las imágenes filmadas de las que surgieron. El periodo de adaptación nunca coincide con las prácticas de los estudiantes en los centros educativos y este era un motivo más para tomarlo como tema.

Tema 2. Cuerpo y jornada escolar.

Los estudiantes contaban con los pdf de los relatos escolares ilustrados de fechas: $24.10 .2011 ; 2.10 .2012$ y 1.10.2013. El motivo de la elección se debía a que era la primera fecha en cada uno de los niveles del ciclo que el alumnado había hecho el recorrido previsto en la jornada escolar: primera hora en el aula y segunda en la salagimnasio. Una vez en clase verían las imágenes filmadas de las que surgieron. El relato escolar, por tanto, se refiere a un tramo de la jornada escolar, el que transcurre entre las 12 y las 13 horas, aproximadamente.

Los estudiantes conocen otras experiencias, han cursado ya el primer periodo del Prácticum, pueden contrastar con sus saberes previos la información que aquí reciben.

Tema 3. Tratamiento educativo del ámbito corporal en el segundo ciclo de Educación infantil.

La lección en la sala-gimnasio. La primera lección desarrollada a los 3, 4 y 5 años. Los estudiantes contaban con los pdf de los relatos escolares ilustrados de fechas: 24.10.2011; 2.10.2012 y 1.10.2013, en esta ocasión haciendo referencia a lo ocurrido en la sala-gimnasio, es decir, a la segunda hora de mi visita. En clase verían las imágenes filmadas de las que surgieron.

Tema 4. Tratamiento educativo del ámbito corporal en el segundo ciclo de Educación infantil. 
3 años. Unidad de aprendizaje: "Desplazamientos motrices coordinados, atrevidos, veloces y conscientes". Los estudiantes contaban con los pdf de los relatos escolares ilustrados de fechas: 21.11.2011 y 28.11.2011 y, en clase, veríamos juntos las imágenes filmadas de las que habían surgido. Se trata de dos lecciones enlazadas en las que puede observarse el desarrollo de la unidad de aprendizaje mencionada.

Tema 5. Tratamiento educativo del ámbito corporal en el segundo ciclo de Educación infantil.

4 años. Unidad de aprendizaje: "Sobre la autonomía del alumnado". Los estudiantes contaban con los pdf de los relatos escolares ilustrados de fechas: 13.11.2011 y 20.11.2011 y, en clase, veríamos juntos las imágenes filmadas de las que habían surgido. Cómo se puede observar, las fechas en las que se desarrollan los Procesos prácticamente coinciden con las del tema anterior y también lo harán con los del tema siguiente, es fruto de la decisión de utilizar en su elección un criterio lo más externo posible.

Tema 6. Tratamiento educativo del ámbito corporal en el segundo ciclo de Educación infantil.

5 años. Unidad de aprendizaje: "Utilizando y mejorando las habilidades de manipulación hasta jugar juntos". Los estudiantes contaban con los pdf de los relatos escolares ilustrados de fechas: 26.11.2013 y 3.12.2013 y, en clase, veríamos juntos las imágenes filmadas de las que habían surgido.

No podíamos abordar más allá de catorce relatos, dado que como ya dije contamos con quince semanas para el desarrollo de la asignatura, por lo que elegimos los relatos escolares mencionados procurando que los estudiantes pudieran hacerse una idea general de las preocupaciones que una maestra de Educación Infantil en relación con el tratamiento educativo del ámbito corporal. ${ }^{4}$

Durante las cinco primeras semanas del desarrollo de la asignatura, los temas presentados hacen referencia a "Cuerpo y jornada escolar". Los relatos escolares expuestos informan a los estudiantes sobre los esfuerzos de la maestra por conseguir que las situaciones educativas que propone en el transcurrir del tiempo escolar y los

\footnotetext{
${ }^{4}$ Por motivo de extensión, no expongo los relatos escolares mencionados y que los estudiantes reciben. Si el lector estuviera interesado por ellos, podríamos plantearnos el hacérselos llegar a través de mvaca@mpc.uva.es
} 
enlaces que se producen para pasar de una a otra, permitan a los niños y niñas moverse en un ambiente en el que es posible el "progreso".

Cualquier educador comprometido con la vida de un niño, el objetivo principal es educarlo de tal modo que le permita progresar.

D. J. Siegel y T. Payne Bryson $(2013,9)$.

Este ambiente depende en gran medida de la gestión que va haciendo la maestra con las diferentes presencias corporales que van apareciendo en el aula. Los relatos escolares del periodo de adaptación y de la primera visita a los 3,4 y 5 años, pueden ayudar a comprender esta preocupación profesional.

Durante las diez semanas restantes, los temas presentados hacen referencia a la Educación Corporal Infantil. Primero, explicando la estructura de funcionamiento en la que se desarrollan las lecciones centradas en el tratamiento educativo del ámbito corporal. Después, presentando tres Unidades de Aprendizaje, una en el nivel de 3 años, otra en el nivel de 4 años, y una tercera en el nivel de 5 años.

Para seleccionar las Unidades de Aprendizaje a exponer hicimos un sorteo utilizando los diferentes momentos del curso escolar, esta es la razón de que las fechas de planificación, implementación y evaluación que pueden observarse en los vídeos y leerse en los relatos coincidan en la segunda quincena de noviembre.

\subsection{Valoración de los estudiantes sobre la formación adquirida en el trabajo con} los relatos escolares

En los momentos finales del desarrollo de la asignatura, tratamos de conocer cuál era la relación que los estudiantes establecían entre el trabajo desarrollado con los relatos escolares (lecturas; visionado de las películas; análisis compartidos;...) y su formación como maestros de Educación Infantil. Les formulé la pregunta de forma muy abierta. Simplemente les invité a escribir sobre el valor que concedían a los relatos escolares en su formación como aprendices de maestro, en los temas relacionados con la Educación Corporal Infantil.

Las respuestas fueron múltiples y complejas y, después de dar muchas vueltas a la manivela, lo que no ha impedido que siga en ello, traté de agrupar las reflexiones de los estudiantes en torno a las Competencias Específicas de la asignatura y los Resultados de Aprendizaje que se esperan de ella. 
La asignatura "Fundamentos y Didáctica de la Educación Corporal Infantil" pretende que los estudiantes se capaciten:

1. En el conocimiento comprensión y experimentación de metodologías con las que llevar a cabo procesos de enseñanza-aprendizaje sobre el ámbito corporal en educación infantil.

2. En analizar y valorar modelos, experiencias innovadoras y artículos científicos sobre Educación corporal infantil.

3. En la elaboración de propuestas curriculares sobre la Educación corporal infantil.

4. En planificar, implementar y evaluar procesos de enseñanza, aprendizaje y evaluación.

Transcribí sus reflexiones en letra cursiva bajo los títulos de las competencias a adquirir e hice un comentario a sus respuestas. Cuando devolví el trabajo elaborado para comentarlo con los estudiantes, éstos decidieron que detrás de cada reflexión debería ponerse el nombre real del autor, o el apellido si el nombre era repetido, y no ocultarlo tras un número, que era lo que yo había puesto, y así lo presento, respetando su expreso deseo.

Capacitarse en el conocimiento comprensión y experimentación de metodologías con las que llevar a cabo procesos de enseñanza-aprendizaje sobre el ámbito corporal en educación infantil.

"Los relatos han sido, a lo largo de esta asignatura, de gran importancia en nuestro proceso de construcción de aprendizaje, dándonos una visión que va más allá de lo teórico, nos hace reflexionar sobre los contenidos de esta asignatura, nos informa de los que son posible impartir en las aulas..."

\section{Zoe}

Los relatos nos hacen ver que dar cuenta de lo que sucede en la sala es el mejor elemento para reflexionar sobre lo sucedido, ya que ello junto con la observación sistemática son los mejores elementos a tener en cuenta para analizar el transcurso de la lección, los aprendizajes que tienen lugar, la forma de actuar de cada niño, las previsiones para la siguiente lección, etc."

\section{Cuende}


"Los relatos escolares nos ofrecen gran cantidad de información relativa al día a día en un aula determinada. Nos han permitido conocer cómo se desarrolla parte de la jornada..., qué estrategias emplea la maestra para motivar, trabajar e involucrar al alumnado en los aprendizajes. Además, los relatos que hemos ido viendo nos han acercado a las características que tiene el grupo de forma conjunta y las individuales de cada niño y de cada niña y de cómo estas influyen notablemente en la implicación, en la disposición y en el desarrollo de la práctica en la sala de psicomotricidad".

\section{Verónica}

Comentario

Los estudiantes valoran en los relatos la vinculación entre la Didáctica, qué enseñar, su porqué y para qué, y la Pedagogía, el modo de llevarlos a cabo. Encuentran en los relatos contenidos experimentados, contenidos que ven posible impartir.

En cuanto a la metodología con la que se llevan a cabo los procesos de enseñanza, aprendizaje y evaluación destacan la importancia de retomar lo ocurrido en el aula para después analizarlo y tomar decisiones. Dan detalles sobre por qué la consideran una buena metodología, al parecer ven en ella una posibilidad de: observar el comportamiento y la construcción del aprendizaje de los niños vía corporal, un cuerpo que actúa, se expresa, se relaciona, se desarrolla adquiriendo diferentes competencias; conocer al niño y la niña en su originalidad y en su relación con la originalidad de los otros; obtener información para prever la acción en nuevas situaciones educativas; observar el trabajo de la maestra -su futuro trabajo-; comprender la complejidad de la práctica, sus múltiples detalles;...

Capacitarse en analizar y valorar modelos, experiencias innovadoras y artículos científicos sobre Educación corporal infantil.

Por otra parte, al ser relatos de los mismos niños y niñas en tiempos diferentes, podemos observar: sus progresos; cómo las actividades aumentan en dificultad y complejidad; y cómo los niños logran los objetivos que se persiguen.

\section{Rosario}

“[En la universidad] No solemos ver cómo se lleva a la práctica lo estudiado en clase, sea cual sea la asignatura. En este caso hemos podido ver los resultados e incluso aprender a partir de ellos. Los videos realizados en el C.P. "Miguel Hernández”, han 
servido como método de aprendizaje llamativo y seguro. Con seguro me refiero a que en la universidad pueden decirte cómo van a ser las cosas, pero ese "cómo serán" nunca es igual a "cómo son" y gracias a los relatos escolares mostrados, aprendemos de realidades comprobadas..."

\section{Valencia}

"La gran ventaja que los relatos ofrecen es la relectura. Cada nueva ojeada nos permite descubrir nuevos detalles que antes se pasaron por alto: Volver al recuerdo para modificarlo con nuevos detalles, con nuevas opiniones y puntos de vista, resulta atractivo, motivador y productivo".

\section{Roberto}

"Nos permiten situarnos en un contexto definido... Pueden ser releídos y en cada una de esas lecturas podemos aprender algo nuevo, ir teniendo en cuenta aspectos que nos habían pasado desapercibidos..."

\section{García}

Comentario

Destacan de esta experiencia innovadora el hecho de poder contemplar el mismo grupo de niños con la misma maestra a lo largo de todo el segundo ciclo de Educación Infantil, valoran positivamente esta panorámica prolongada, porque la escuela es un proceso con diferentes ritmos, en la que una mirada puntual tiene un valor relativo.

Califican la experiencia como un "método de aprendizaje llamativo y seguro" y lo explican presentando el modelo analizado como un archivo de "realidades comprobadas"

Valoran el poder releer, volver al texto, para, como dice Steiner, elaborar un "texto de respuesta"

Hacer esto, conociendo otras experiencias innovadoras y habiendo estado en un centro de Educación Infantil durante algo más de dos meses, puede ayudarles en la elaboración del "modelo profesional" (Meirieu, 2004, 168), que van construyendo como aprendices de maestro.

\section{Capacitarse en la elaboración de propuestas curriculares sobre la Educación corporal infantil.}


"Por tanto, los relatos nos ponen los pies en la tierra, dándonos un contexto concreto y una serie de bases a seguir que hacen que nuestros proyectos tengan como referencia un aula real, y no una ideal que no tenga en cuenta la realidad de los niños y caiga en el problema de no poder ser llevada al aula".

\section{Sara}

Comentario

Los relatos escolares ayudan a los estudiantes a observar la complejidad de la práctica, su originalidad contextual, la facilidad con la que se dan imprevistos... Todo ello pone de manifiesto el escaso valor de las programaciones ne variatur, que tanto abundan en los libros de texto y que dicen haber conocido en sus Prácticas de enseñanza. Estas reflexiones les van capacitando para la elaboración de propuestas curriculares sobre educación corporal infantil.

\section{Capacitarse en planificar, implementar y evaluar procesos de enseñanza, aprendizaje y evaluación.}

"La realización de la Unidad de aprendizaje sin los relatos ni los vídeos habría sido muy complicada o casi imposible, pues ver el transcurso de lecciones reales pudiendo pausar y hacer incisos era una gran ventaja".

\section{Solís}

"Sin ellos (vídeos y relatos), creo que mi unidad tendría un resultado bastante distinto, y sobretodo un carácter menos concreto, ya que todo estaría basado en hipótesis, y el hecho de que los sujetos de la planificación sean niños de corta edad lo haría todo mucho menos previsible".

\section{Beatriz}

"Se trata de una valiosa fuente de información a partir de la cual resulta más sencilla la comprensión, la reflexión y el análisis... Ahora que estamos empezando y que nos falta experiencia, los relatos nos sirven de apoyo y de inspiración para nuestros proyectos, y gracias a ellos tenemos la ventaja de que ya sabemos lo que va a suceder porque lo tenemos ahí narrado, por tanto nos resulta más sencilla la realización de previsiones sobre las prácticas, y gracias a que tenemos la visión de todo el ciclo porque contamos con relatos de 3, 4 y 5 años; podemos hacernos una idea generalizada 
de los progresos y las limitaciones de los niños en las diferentes lecciones de las unidades de aprendizaje"

\section{Irene}

"En definitiva, gracias a los visionados y los relatos expuestos en clase, la realización de esta unidad didáctica ha tomado una perspectiva más real, ya que muchas de las cuestiones tratadas en ella he podido constatar su realización en una clase real, no de una forma hipotética".

\section{María}

"En los relatos podemos comprobar que siempre surgen imprevistos y que no se puede realizar todo lo planificado. Así, nos permiten saber que cada día en la sala es distinto porque hay que adaptar la planificación del proyecto a las necesidades de los niños y a la disposición e implicación que presentan in situ.

\section{Calvo}

"Los relatos escolares ofrecidos sobre las lecciones de psicomotricidad han sido esenciales a la hora de programar esta unidad de aprendizaje para niños de 4 años sobre la autonomía personal. Esto se debe a varias razones. En primer lugar, porque nos acercan a un contexto real, con niños reales en situaciones que se desarrollan de verdad y no son ni supuestas ni idealizadas. A la hora de planificar, gracias a la lectura $y$ visionado de los relatos, he podido ver cómo reaccionan y progresan los niños ante las diferentes tareas propuestas, cuáles son sus intereses y necesidades, etc. Bien es verdad que cada clase es un mundo, pero los relatos nos acercan a esa realidad que nosotros de momento solo conocemos a través del Prácticum. Y qué mejor que acercarnos de la mano de una profesora de Ed. Infantil que se la ve que sabe y controla sobre temas educativos con distintas estrategias, metodologías, materiales, recursos...que podemos ir recopilando y añadiendo a nuestra formación para en un futuro aplicarlas en nuestra clase, ya que las considero como buenas prácticas y experiencias sobre la Ed. Infantil"

\section{Carlota}

Comentario

Algunos estudiantes sitúan el trabajo desarrollado con los relatos escolares como una necesidad para poder abordar las tareas de planificación, desarrollo y evaluación de las 
unidades de aprendizaje. Al parecer, les ayudan a comprender que las unidades de aprendizaje son procesos dinámicos, que reclaman negociaciones para establecer equilibrios entre las tendencias discente y docente, entre el proyecto general y los proyectos particulares que se dan dentro, entre la estructura que generan las relaciones sociales y la que genera la tarea disciplinar.

Observar estos equilibrios en los relatos escolares les lleva a afirmar que las unidades de aprendizaje expuestas nos son "supuestas, ni idealizadas".

Comparan los relatos escolares con los aprendizajes obtenidos en el Prácticum I, lo que viene a otorgarles una importancia que debería ser tenida en cuenta en las facultades de formación de maestros.

Estas reflexiones abren la discusión a un contexto mayor que el que supone una asignatura concreta del plan de estudios centrada en una disciplina determinada, la educación corporal infantil.

Hay aprendizajes, que los estudiantes dicen haber construido, que no se encuentran entre los señalados en la Guía Didáctica de la asignatura.

"El texto ilustrado nos aporta información extra a lo que podemos observar en los vídeos... En definitiva, el relato es una buena herramienta para guiar nuestra pensamiento y para obtener otros puntos de vista distintos al que nosotros construimos cuando, simplemente, hacemos el visionado de las lecciones..."

\section{Evelin}

“Además de la información aportada por la trascripción de lo sucedido en la salagimnasio, los comentarios y reflexiones personales realizadas por el observador externo ayudan a entender el proceso desde otra perspectiva".

\section{Llana}

"Lo visual siempre llama más la atención para el aprendizaje, pero la memoria es selectiva y a veces olvidadiza y no podríamos haber trabajado como lo hemos hecho sin el apoyo de los relatos, los cuales personalmente he consultado mucho a lo largo de la asignatura, sobretodo en esta última parte para la realización de mi unidad de aprendizaje".

\section{Raquel}


Comentario

Con estas reflexiones se abre una interesante discusión sobre la oportunidad formativa que supone la elaboración de los relatos escolares. Al parecer, para que éstos sean útiles en la formación de los maestros necesitan estar situados dentro de un modelo profesional en el que encuentran sentido, dentro de lo que Schön $(1998,242)$ denomina una "teoría abarcadora"

"Una teoría abarcadora que proporciona un lenguaje con el que construir descripciones concretas, y temas con los que desarrollar interpretaciones particulares,...Si un profesional tiene una teoría así, la utiliza para guiar su reflexión desde la acción."

\subsection{Conclusiones}

Los relatos escolares, al ser textos ilustrados que describen la práctica con precisión, cubren la necesidad de los maestros reflexivos que siguen metodologías de investigación-acción colaborativa, pues el análisis tiene más dificultades para dispersarse a la vez que aumentan las posibilidades de ser compartido con otros.

Contar con las reflexiones de los estudiantes, agrupadas en torno a las Competencias y los Aprendizajes señalados en la Guía de la asignatura, nos permite contar con unos recursos extraordinarios en el desarrollo de los procesos de enseñanza y aprendizaje que tienen lugar en esta asignatura de formación inicial de los Maestros de Educación Infantil. Gracias a ellos, el saber no solo emana del profesor, sino también de las reflexiones que ellos mismos van elaborando buscando el conocimiento y la formación profesional. Esta complicidad entre la enseñanza y el aprendizaje, entre la tendencia docente y la tendencia discente nos permite acercarnos a lo que Meirieu (1996, página 68) denominaba la astucia de Rousseau.

La no poca "astucia” de Rousseau consiste, pues, en organizar la pedagogía en torno al "interés del niño", pero de tal modo que este último, gracias a escenificaciones sabiamente montadas, vea una convergencia entre "lo que le interesa" y "lo que va en su interés".

\section{Líneas abiertas a la indagación}

La asignatura "Fundamentos y Didáctica de la Educación Corporal Infantil", se imparte, como ya indiqué, en tercer curso en el Grado de Maestro de Educación Infantil. 
En cuarto curso los estudiantes que así lo soliciten tiene la posibilidad de ordenar las asignaturas optativas en torno a dos menciones, una de ellas, denominada: "Expresión y comunicación artística y psicomotricidad”. En esta mención, hay una asignatura, cuyo desarrollo compartimos a partes iguales profesorado de Plástica, Música y Educación Corporal, denominada "Análisis y diseño de proyectos educativos de las áreas de expresión”. En ella, como profesor encargado de la Educación Corporal, he tenido la oportunidad de mostrar al mismo grupo de estudiantes que había dado clase en "Fundamentos y Didáctica de la Educación Corporal Infantil", nuevos relatos escolares, pertenecientes a otras unidades de aprendizaje desarrolladas en la Experiencia CEIP "Miguel Hernández”, que permiten conocer nuevos procesos de enseñanza y aprendizaje desarrollados por el mismo grupo de alumnos bajo la coordinación de la misma maestra: se analiza de nuevo el tema de "cuerpo y jornada escolar" en otro momento del curso, el mismo en tres, cuatro y cinco años; y se estudian nuevas unidades didácticas desarrolladas en cada uno de los niveles del ciclo.

La intención es ayudar a los estudiantes a analizar y diseñar proyectos educativos en aquello que tiene que ver con el ámbito corporal, como les solicita la asignatura. Los relatos escolares vuelven a mostrarse muy oportunos para continuar con las reflexiones particulares y con los debates que se establecen en torno a ellas.

El plan de estudios continúa en vigor y, al parecer, seguirá en los próximos cursos, lo que nos permitirá seguir analizando lo ocurrido y precisando los proyectos de trabajo en relación con el uso de los relatos escolares como recurso de formación en las asignaturas mencionadas.

En ocasiones, de forma puntual, se nos requiere, por parte de algún Centro de Profesores o de algún centro educativo en particular, para impartir ponencias a maestros y maestras de educación infantil que se encuentran trabajando en el segundo ciclo, 3-6 años y que están interesados por el Tratamiento Educativo del ámbito Corporal en estas edades. También en estas ocasiones utilizamos relatos escolares elaborados en la Experiencia CEIP “Miguel Hernández”.

Siempre que lo hago, vuelvo sobre la sentencia de Loren Stenhouse $(1987,81)$ :

la investigación sólo puede perfeccionar notablemente el arte de enseñar si unas hipótesis cuya aplicación cabe comprobar porque pueden ser puestas a prueba en el aula por parte del profesor, y si ofrece descripciones de casos o 
generalizaciones retrospectivas acerca de casos suficientemente ricos en detalles para proporcionar un contexto compartido en el que juzgar el propio caso.

Los relatos escolares sin duda proporcionan de manera extraordinaria la identificación de las hipótesis a evaluar dentro de ese relato, que describe la historia de un aula en un tiempo determinado, rico en detalles, que en no pocas ocasiones proporciona un contexto compartido en el que juzgar el propio caso.

Últimamente, los estudiantes que cursan la asignatura "Fundamentos y Didáctica de la Educación Corporal Infantil" tienen una doble procedencia, además del grupo de estudiantes de tercer curso en el Grado de Maestro de Educación Infantil ya mencionado, que la sigue cursando en el segundo cuatrimestre, después de haber realizado el Prácticum I en centros escolares de Educación Infantil, hay un grupo de estudiantes, matriculados en la "Titulación conjunta", que realizan a la vez los estudios de Grado de Maestro de Educación Primaria y el Grado de Maestro de Educación Infantil, que aún no han realizado ningún tramo del Prácticum cuando la cursan.

Con este segundo grupo no se dan, obviamente, referencias a otros grupos escolares con los que comparar lo que observan en los vídeos y en la lectura de su relato.

En la segunda semana del desarrollo de la asignatura propuse que cada estudiante de ambos grupos debería escribir no más de media página sobre el interés de los relatos escolares en su formación como maestro, maestra. Cuando leí las respuestas de este segundo grupo observé que abundaban las opiniones generales del tipo: los relatos escolares son muy importantes, pero resultaba complicado identificar alguna cuestión que concretara dicha importancia. Al parecer, el no tener otras referencias para analizar y valorar lo que habían visto y leído, los mensajes sobre el interés en su formación se diluían. Expongo a continuación algunas de sus reflexiones:

- "Me llama la atención el comportamiento de la maestra, sus pretensiones, sus dificultades, su enorme trabajo, su paciencia."

- "Es una práctica muy real, gracias a ella sé más sobre el trabajo que hacen las maestras con los niños."

- "He observado que lo que se hace en la escuela se va organizando en tareas concretas y en ellas se puede ver su porqué y para qué."

- "Se les trata con mucho cariño"... 
Les comenté que ellos estudiaban para capacitarse en el desarrollo de un trabajo como el que habían observado, que también ellos deberán proponer situaciones educativas, que también tendrán que mostrar esa empatía, paciencia y cariño que algunos habían señalado.

Al parecer el análisis de los relatos escolares ayuda, en estos casos, a tomar conciencia del significado de los estudios elegidos, y a mí aterrizar mis mensajes entre los conocimientos previos de los estudiantes.

La actividad propuesta me permitía contrastar las respuestas en un grupo y otro. En el primer grupo: Organizan las reflexiones desde diferentes perspectivas, desde la figura de la maestra, el alumnado, y el currículo y la pedagogía que en cada situación educativa se va poniendo de manifiesto; Hablan de empatía, cercanía, paciencia, entusiasmo, autoridad, de los recursos y estrategias pedagógicas que permiten que haya un ambiente de contención y que el paso de una situación educativa a otra no sea un caos; Identifican el ámbito corporal como un lenguaje que posibilita actuar, expresarse, comunicar, relacionarse,... No me quedaba duda de que el interés de los relatos escolares y su análisis se transforma en función de los conocimientos previos sobre la escuela y sus funciones. El haber pasado, o no, por la asignatura de Prácticas en un centro educativo aparece como bastante determinante.

Los relatos escolares se han ido imponiendo en mis actividades de formación de maestros, tanto de formación inicial como permanente, espero ir dando cuenta de su valor en nuevas ocasiones.

\section{Referencias bibliográficas}

Elliot, W. E. (1998). El ojo ilustrado. Indagación cualitativa y mejora de la práctica educativa. Barcelona: Paidós.

Meirieu, P. (1996). Frankenstein educador. Barcelona: Alertes.

Meirieu, P. (2004). En la escuela hoy. Barcelona: Octaedro - Rosa Sensat.

Schön, D. (1998). El profesional reflexivo. Cómo piensan los profesores cuando actúan. Barcelona: Paidós.

Siegel, D. y Payne, T. (2013). El cerebro del niño. Barcelona: Alba Editorial.

Steiner, G. (2006). Sobre la dificultad y otros ensayos. México: Fondo de Cultura Económica. 
Stenhouse, L. (1987). Investigación y desarrollo del currículum. Madrid: Editorial Morata.

Vaca, M. J. (2006) ¡Estoy dentro de mi cuerpo! Revista Cuadernos de Pedagogía, 353, 26-29.

Vaca, M. J. (2005). La integración de las actividades motrices acuáticas en la educación fisica escolar. Palencia: Patronato Municipal de Deportes.

Vaca, M. J. y Varela Ferreras, M. S. (2008). Motricidad y aprendizaje. El tratamiento pedagógico del ámbito corporal (3-6). Barcelona: GRAÓ

Vaca, M. J. y Sagüillo Rodríguez, M. (2009). El tablero en las lecciones de Educación Física Escolar. Su contribución al aprendizaje. Educación física y deporte, 28, 1, 85-102.

Vaca, M. J.; Fuente Medina, S.; Santamaría Balbás, N. (2013). Cuñas motrices en la Escuela Infantil y Primaria. Logroño: Ediciones Quintana. 